\title{
Quality Improvement in Construction by Using a Vandermonde Interpolation Technique
}

\begin{abstract}
Cost and quality are considered as the two most important elements in all construction activities. However, the quality of products or services does not focus only on their ultimate delivery, but also on the quality of the whole business model. Prevention-Appraisal-Failure (PAF) modelling is the most commonly adopted methodology to assess the quality performance of the construction organization. However, it cannot successfully show the correlation between prevention, appraisal, and failure costs, hence, it is difficult to determine the optimal point among these costs. A case study is proposed in this paper by presenting activities of a hydro-seeding company. Quality management data of the company are also attached and analysed by using a Vandermonde interpolation technique. This new method clearly shows an optimal point of the total cost which is a summation of prevention, appraisal and failure costs. Comparisons with the PAF modelling of the data are made. Data interpolation can also be used to thoroughly study the company's performance in terms of investment and managing its resources.
\end{abstract}

Keywords: prevention-appraisal-failure, quality management, construction, Vandermonde interpolation. 


\section{Introduction}

Less satisfactory performance in the construction industry has led to the belief that construction products cannot be completed within budget and desired quality [1]. Although quality management is implemented by many organizations, serious problems can still be found in construction sites [2]. Without an effective quality cost system in place, performance improvement can be very difficult to identify and measure [3].

The major problems that cause costly errors in construction are $[4,5]: i$ ) inadequate training and management of designers. The results of low quality design are variation orders and claims due to frequent changes in the detailed information throughout the project's construction process; ii) inadequate or incorrect specifications in the tender; iii) inadequate definition of responsibilities within management groups both in the office and on site; $i v)$ poor communication among parties involved in the contract, leading to confusion and costly delays; $v$ ) inadequate training and management of the construction labour force on site; and vi) inadequate verification procedures and policies to ensure that design, materials and workmanship meet specific requirements.

Higher product quality standards have increasingly become necessary around the world. To accurately measure quality performance in the industry, costs of achieving high quality have been strongly advocated by many researchers [1, 6-13]. The costs spent on having high quality models could help organizations to save up to $30 \%$ of the total manufacturing costs [14]. PreventionAppraisal-Failure (PAF) modelling is significant for firms to effectively control and to sustain competitive advantage.

However, most organizations have found difficulties in balancing prevention and appraisal costs, and failure costs. PAF modelling does not provide numerical solutions to how much organizations 
should invest to a particular activity. Construction organizations are hence confused on the effectiveness in using PAF modelling to estimate the coverage percentage of their investment. The main advantage of using interpolation in PAF modelling is because of its accuracy, i.e. fine details in the data set will not be averaged out as in the case of using the PAF modelling method, but they can be retained by polynomials for in-depth analyses. It is evident from previous work in the literature that the optimal point could not be located [15-17, 14] by using PAF modelling method which did not help understanding the company's activities and performance over a given time period. Thus, possible ways of finding the optimal point has been one of the most popular research directions in recent years. Motivated by the effectiveness and usefulness of interpolation which has been widely employed in the field of signal processing, this paper proposes the use of a Vandermonde interpolation technique which can give a better fit to the data collected from the company.

The aims of this paper are:

- To investigate the importance of quality in construction;

- To review the theory of prevention-appraisal-failure modelling;

- To use the Vandermonde interpolation technique to best-fit the data collected from a hydroseeding company;

- To show the location of the optimal point(s) in the total cost which is a summation of the prevention, appraisal and failure cost;

- To compare the performance of the PAF modelling and the Vandermonde interpolation technique; and

- To establish that interpolation techniques are useful in the field of quality management. 


\section{The Importance of Quality}

Establishing the project requirements for quality begins at project inception. A careful balance among owner's requirements of the project costs and schedule, desired operating characteristics, materials of construction, and the design professional's need for adequate time and budget to meet those requirements during the design process is essential [18]. The purpose of project quality management is to ensure that the project meets its requirements [19]. It should be noted that project management involves meeting or exceeding stakeholder needs and expectations. The project team must develop good relationships with key stakeholders, especially the main customers for the project, so that the concept of quality is thoroughly understood. After all, the customers ultimately decide if the project quality is acceptable. Many technical projects fail because the project team focuses only on meeting the written requirements for the main products and ignores other stakeholder needs and expectations from the project.

Quality management plays a major role in construction companies [20]. The quality of production line is crucial to the delivery of quality products. Quality, therefore, must be on an equal level with project scope, time and cost [19]. If a project's stakeholders are not satisfied with the quality of the project management or the resulting products of the project, the project team will need to adjust scope, time and cost to meet stakeholder needs and expectations. Hence, meeting only written requirements for scope, time, and cost is simply not sufficient.

\section{Prevention-Appraisal-Failure Model}

The quality of products or services does not only focus on their ultimate delivery, but also on the quality of the whole business process. To provide optimum benefits, companies should apply the most reasonable and cost effective method to achieve client satisfaction. Nowadays, organizations are faced with accelerating and unpredictable rates of changes in areas such as technology, demography market preference, patterns of work and legislation, in which it will only survive if its 
employees are effectively trained and fully committed to its growth and development [21]. This commitment stems from a real sense of personal involvement, respect and value. The industry is rife with examples of substandard work, shoddy workmanship, cost overruns and project delays. There are also frequent complaints about poor quality of fittings and finishes of newly completed residential buildings in both the public and the private sectors [2]. The uplifting of construction quality requires a change of mindset among all industry participants so that everybody is committed to achieve excellence rather than merely to meet the minimum acceptable standards [2]. The entire project team should aim to deliver a total quality product that not only meets the client's and endusers' requirements in all respects, but it is also completed on time, at a reasonable cost, and in a safe and environmentally responsible manner [22]. To drive towards excellence, all sectors of the construction industry must develop a performance-oriented culture with an emphasis on seeking continuous improvement rather than adopting short-term and project-based approaches.

Improving product quality and reducing product cost are the two main management tasks for an organization. Reviews from Aoieong et al. [23] and Tang et al. [17] provided a comprehensive methodology and procedure in choosing suitable models in cost of quality for various types of activities. Among them, the PAF modelling method can be used to achieve this goal (see Figure 1). The terms used in the PAF modelling method are defined as follows [24]:

1. Prevention cost: costs associated with activities undertaken to prevent or reduce failures;

2. Appraisal cost: costs associated with the assessment of conformance to requirements and detection of failures. For landscape hydro-seeding activity, it is the costs of inspection and testing; and

3. Quality failure cost: costs arising within the organization as a result of a detected quality failure before and after transferring customers.

The total costs on the PAF models are given in Eq. (1): 
$<$ Figure $1>$

As shown in Figure 1, the failure costs are very high corresponding to low quality and vice versa, because of a higher defect rate and the entire production line is in a chaotic situation [24]. If the perfection rate slightly decreases, prevention and appraisal measures are more relaxed. This further increases the product defect rate, lowers customer confidence and results in much higher external failure costs. Internally, accidents worsen the situation in chaotic production lines and therefore resulting in higher defect rates.

The link between cost and quality, showing company's quality costs, are likely to change with changing quality levels in the process of the cost modelling and Prevention-Appraisal-Failures (PAF) models [25], which showed that quality levels were improved by greater investment in prevention and appraisal methods, the costs of failure felt quite dramatically, but beyond a certain point significant further investment would only produce modest reductions in failure costs. The resultant total quality cost curve will therefore initially fall to the optimum cost level, then rising again as improvements are gained.

\section{Interpolation Using the Vandermonde Matrix}

Interpolation using polynomial fitting is a technique which uses polynomials of order up to 20 to fit a given set of data. This technique is well known because it is much better than the linear regression method of simply assigning the line of best fit to the data. Given a set of data of the form $x(1)$, $x(2), \ldots, x(N)$, with values of $y(1), y(2), \ldots, y(N)$, where $N$ is the data length. The coefficients $c_{1}, c_{2}$, $\ldots, c_{N}$ of the interpolating polynomial which can be used to "best fit" the data are related to the input $x$ and output $y$ via the Vandermonde matrix of the form 


$$
\left[\begin{array}{ccccc}
1 & x_{0} & x_{0}^{2} & \ldots & x_{0}^{N-1} \\
1 & x_{1} & x_{1}^{2} & \ldots & x_{1}^{N-1} \\
\ldots & \ldots & \ldots & \ldots & \ldots \\
1 & x_{N} & x_{N}^{2} & \ldots & x_{N}^{N-1}
\end{array}\right]\left[\begin{array}{c}
c_{0} \\
c_{1} \\
\ldots \\
c_{N}
\end{array}\right]=\left[\begin{array}{c}
y_{0} \\
y_{1} \\
\ldots \\
y_{N}
\end{array}\right]
$$

where the $c$ matrix consists of important coefficients of the polynomial. It should be stressed that the $c$ matrix does not always exist; prompting that extra care must be taken when using the technique to interpolate different data sets.

The new interpolating polynomial is thus given by:

$y_{\text {interpolate }}=c_{0}+c_{1} x+c_{2} x^{2}+\ldots+c_{N} x^{N}$,

which can be used to mathematically model the given data. It should also be noted that $y_{\text {interpolate }}$ generally resembles the shape of the fitted data. However, sometimes, it is difficult to find all the coefficients for a particular data set. Thus, if this method works, then the process of studying and simulation the data set becomes much easier and less time consuming as $y_{\text {interpolate }}$ can now be validly used. However, no numerical methods can completely simulate a given set of data, thus, there exists some marginal errors in curve fitting which generally do not significantly alter the results obtained by analysing $y_{\text {interpolate }}$.

The interpolating polynomial can be found by using the MATLAB package via the command "polyfit". The order of the polynomial is required as an important parameter. For this particular set of data, we have found that orders of 7 and below yield sensible results which are useful to understand the relationship between prevention, appraisal and failure costs. It should also be noted that the higher the order of the polynomial, the better the fit to the data. However, for data consisting of many abrupt changes, high-order polynomials cannot satisfactorily interpolate the data as in this case the data can be considered to be abnormal and the number of existing coefficients cannot be found by using the Vandermonde matrix. 


\section{Case Study}

This section outlines one typical case study using cost data from a hydro-seeding company in which it is found that the PAF modelling method is difficult to find the break-even point(s) or minimumcost point(s) to optimize the costs of prevention, appraisal and failure. The total cost of the company is then plotted as a function of quality. The break-even points or minimum-cost points are locations at which the total cost is minimum. It should be stressed that the location of the break-even point(s) is important to assess the company's performance which has not been thoroughly studied and analysed even though a number of works on this topic have been reported in the literature. The main difficulty has been that the PAF modelling method could not retain the fine details in the data, i.e. they are averaged out, which made the data curves flat and resulted in misleading analyses. By using the Vandermonde interpolation technique, it is possible to show the fine details in the data given that an appropriate polynomial order is used. However, if the order is too high, i.e. approaching 20 and larger than 10, then the technique will not yield sensible solutions as explained in Section 4. Thus, care must be taken when applying this technique as it is not always the case that the higher the order the better the results and vice versa. Trial-and-error methods are used to work out the appropriate polynomial order for a particular data set, i.e. the order which gives the clearest location of the break-even point should be chosen. From that, the company's overall performance can be assessed.

\subsection{Background on the company}

This research uses a pilot study approach to improve the quality performance in Hong Kong hydroseeding industry. A landscape hydro-seeding company is selected to review and to analyse the projects quantitatively. All staff members were also responsible for quality on site through selfmonitoring and observation. The supply chain employees, including suppliers, subcontractors, designers, clients, project managers, site agents, quantity surveyors and junior staff, were all 
involved in recording and collecting data such as being responsible for filing incidents and suggesting possible causes for manifested effects.

Because of the rapid growth of the construction work in Hong Kong after 1990, it was found that the market of the vegetation work has increased more than 100 times before [26]. Hence, the source of turf material and labour were not enough to cope with the expansion of construction work. In view of this, the new vegetation technology - hydro-seeding - was introduced by a Japanese investor in 1980, to review and to analyse the company performance reported in this research.

Before 1980, the main business of the interviewed company was turfing work as a family-type small business, it was a partnership company owned by Chinese and Japanese landscape experts. In 1982, it started the introduction of the hydro-seeding technique from America. Two years later, hydro-seeding techniques were adopted by the Hong Kong Government. This company has been expanding to meet the market high demands. As a result, a new business model and business strategy were required. In 1996, the company became a member of an international institution of "international erosion control association". New concepts of management and technology were explored by landscape industrial experts around the world. After one year, this company was awarded an ISO 9002 certificate. In 1998, an alliance was formed with a strategic partner company, which was the biggest environmental conservation and construction company in Japan. The new technology of vegetation known as hydro-mulching was subsequently introduced in Hong Kong. In 2001, another new technology known as Toyo-Mulching System was also used for vegetation on a steep non-soil slope.

Hydro-seeding is the application of grass seeds, fertilizer and mulch in an aqueous solution by spraying. A green marker dye is often added to the mix, and occasionally, soil-stabilizing chemicals are also added. The relative advantages of this planting technique are to have a wide variety of 
seeds, which can then be quickly and cheaply applied to large and/or steep slopes. A fabric layer should be placed over the slope after hydro-seeding activities are completed to reduce raindrop impact and erosion while the grass is established over a period of approximately six weeks. The function of hydro-seeding is not only to create a grass lawn and to provide recreation space to public, but to make vegetation on a steeper soil slope with effective erosion control species of vegetation to prevent surface erosion. The cost is about $\mathrm{HK} \$ 10 / \mathrm{m}^{2}$ and the production rate is about 500 to $5,000 \mathrm{~m}^{2}$ per man-day.

In this research, projects implemented in the financial years from April 2003 to March 2004 and from April 2004 to March 2005 are analysed using the Hyperbolic and Gaussian distributions. Costs in adopting Hyperbolic and Gaussian distributions are divided into costs of prevention and appraisal, and costs of failure. For the hydro-seeding company surveyed in this research, costs of prevention and appraisal mean the costs used to reduce further failures, including monthly review meetings with a foreman to understand the progress and quarter monthly review meetings with workers to assess their working techniques. Except the review meetings held in this company, seven major elements of costs of prevention and appraisal include: $i$ ) training of the engineering clerk and site engineer for the site "information collection of site condition by telephone" which was introduced in December 2002; ii) introduction of the new and advanced hydro-seeding machine in February 2002; iii) upgrading computer systems and introducing an internal e-mail system; $i v$ ) using a digital camera system to record all the work and site conditions during the site operation and investigation by the engineers; v) consulting and meeting with professionals by joining seminars and conferences, which can provide up-to-date information on hydro-seeding activities; vi) providing related books and magazines in the library for improving the knowledge of employees; vii) employing one parttime engineer to help and to improve the performance quality; viii) inspection of hydro-seeding work within 100 days; $i x$ ) undertaking digital photos by engineers during inspection in monitoring the growth condition of grass and site conditions; and $x$ ) carrying out ISO 9001 audition every six 
months, which includes checking, inspecting, filing, recording all reference information in a required format.

The company's costs of quality failures are divided into two major items: costs of handling and costs of rework. Upon completion of the project, if the vegetation is not satisfactory after 100 days, the clients may orally and/or formally lodge a complaint about the company. Engineers should examine situations of ungrown grass for the particular projects, such as site conditions, working environment and others. The costs used by engineers in understanding and investigating the situations are classified as costs of handling. After the engineers have investigated situations of ungrown grass, rework may be required. Therefore, the costs of rework include: $i$ ) extra time spent by engineers; ii) extra time for site meeting and site investigation on work failures; and iii) material, labour and machine for rework. Table 1 shows the company cost of data in terms of prevention, appraisal and failure over a period of two financial years.

$<$ Table 1 $>$

\subsection{Prevention-Appraisal-Failure Modelling}

For this company, two methods are used to measure quality in hydro-seeding activities: $i$ ) coverage: a coverage test will be used after 100 days on hydro-seeding completion; and ii) the number of complaints received: complaints will be divided into oral and written format. The reason of complaints is normally unsatisfactory ungrown grass, which may be due to lack of sunshine, insect attacks or weather conditions. The number of complaints and their nature will be used to quantitatively stimulate quality as given by Eq. (4):

$Q=1-\frac{x_{1}+x_{2}}{M}$

where $Q$ is the quality value of complaints, $x_{1}$ the number of oral complaints received, $x_{2}$ the number of formal complaints received, and $M$ the maximum number of received complaints. 
To model cost against quality, quality can be measured by the percentage of coverage and by the number of complaints. By using the percentage of coverage to measure quality, the costs of prevention and appraisal increase when the quality increases as seen in Figure 2. Costs of failure are inversely proportional to costs of prevention and appraisal, which decrease when quality increases. Furthermore, the company has spent around $\mathrm{HK} \$ 10,000$ to provide better vegetation coverage of hydro-seeding projects for their clients, which shows significant quality improvement.

$<$ Figure 2>

With regard to quality measurement using the number of complaints, Figure 3 shows fewer complaints due to the increase in cost quality for the project. The situation is similar to the case obtained using the percentage of site coverage as shown in Figure 2. When the costs of prevention and appraisal decrease, the costs of failure increase and vice versa. The costs of failure are also relatively lower than the costs of prevention and appraisal.

$<$ Figure 3 $>$

From Figure 2 and Figure 3, it is difficult to show any break-even point. Since the costs of prevention and appraisal are much higher than the costs of failure, it suggests that this company may already use enough investments to prevent failures and to further improve quality.

As it is clear that the PAF modelling method cannot reveal the correlation between the costs of prevention, appraisal and failure, it is necessary to individually study each of these costs by using other more effective methods. One of them is the use of the hyperbolic and Gaussian distributions employing the $6 \sigma$ concept which was reported by Tam and Le [27]. In this paper, the Vandermonde interpolation technique is proposed which can effectively show fine details in the data, hence the location of the break-even or optimal point. The main motivation of using this method is because the Vandermonde interpolation technique has been successfully used in the field of signal and image processing to best-fit a given data set. 


\subsection{Vandermonde Interpolation Technique}

To use the Vandermonde interpolation technique, it is necessary to prepare the data in which the input in this case is the number of complaints or quality, and the output is the cost. There are three different types of costs: prevention and appraisal cost $(P)$, failure cost $(F)$ and total cost which is a summation of $P$ and $F$. Values of $P$ and $F$ are then inputted into the Vandermonde matrix as given by Eq. (2). From that, Eq. (3) which shows the relationship between the output $y$ and and input $x$ is established by the existence of the coefficients c's. As explained earlier, the existence of the coefficients c's does not always occur, for some set of data, these coefficients may not exist and therefore the technique is not applicable. One possible solution to this problem is to reduce the polynomial order which may yield a finite number of coefficients for Eq. (3). Thus, care must be taken in carefully choosing the right order for the interpolation polynomial.

For the data set in this paper, simulation results show that for polynomial orders of less than 7, nonzero coefficients are obtained. It should also be noted that changing the polynomial order does not affect the analyses and outcomes of the data, i.e. the company's performance is still correctly assessed. By using the data set given in Table 1, the prevention and appraisal cost, failure cost and total cost can be mathematically modelled and are given in Figure 4.

$<$ Figure $4>$

Generally, the total cost curve possesses two break-even points: one at the quality of about 0.7 and the other at about 0.85 . It is clear that the second break-even point is better than the first one due to its higher quality and lower total cost as seen in Figure 4. Unlike the prevention and appraisal cost curve, the total cost curve is aperiodic and appears to be random. Further, the results obtained by using the Vandermonde interpolation technique are consistent to what reported in theory [28]. One concern is the high peak occurring in the failure cost curve at the quality of about 0.75 which can be caused by the start of a new strategy in the company. The prevention and appraisal cost curve is 
relatively constant with small oscillation ripples, which means the curve is periodic and we can effectively model the total cost based on the failure cost. Due to the periodicity in the prevention and appraisal cost of this company, it can be suggested that the company employs strategies of periodically feeding its prevention and appraisal cost program to prevent failures, which is a common practice in the industry. The above findings thus validate the results obtained by the new method. However, it is clear that the failure cost and total cost do not obey the periodicity of the prevention and appraisal cost, suggesting that periodic feeding of prevention and appraisal cost may not be appropriate for this particular company. One possible solution to this problem is to instantaneously monitor the failure cost, which appears to be random in nature, not periodic so that managers can act appropriately when failures start increasing. This can save the company's resources when the failure cost remains constant but the company blindly supplies resources as the periodic cycle is due. It is believed that the periodic nature of the prevention and appraisal cost is widely employed by most companies in the construction management industry as they do not know when failure cost rises. However, by closely examining the second break-even point shown in Figure 4, it is clear that eventually, the company reached its goal of improving quality by using periodic strategies for its prevention and appraisal cost. A number of key questions are:

(1) When do the desirable results occur? and,

(2) By the time the company reaches its satisfactory results, is it too late?

Clearly, there is a trade-off between blindly supplying resources to prevent failures, and to constantly monitor when actual failures occur. It should be noted that the trade-off mentioned above can be mathematically studied and can also be obtained by using common sense. First, it is the company that determines how they want to invest in a long term or a short term. Normally, it is not always true that if a lot of resources are spent over some particular areas, then these areas are expected to be improved. In this case, if the company invested a large amount of its resources at the beginning of the prevention-appraisal periodic cycle, then it would not be better off since it had to 
wait for the entire cycle to finish before seeing the desirable results of achieving higher quality. In the mean time, if the company understood that it was just at the beginning of its periodic cycle, then it should wait and invest its resources somewhere else, which is shown to be more economical. However, one can also ask a question: "How does the company know where it is at when it first started the project?" This is a sensitive and difficult question to answer as to thoroughly know the prevention-appraisal cycle, a substantial amount of data are required. Thus, prior to investing to some particular areas or programs, the company should model and simulate its investment activities, generate a simulated set of data to roughly predict when the cycle starts, then it would have a better chance of increasing its efficiency.

\section{Conclusion}

The quality of products or services does not only focus on their ultimate delivery, but also on the quality of the whole business process. This research aims at reviewing and measuring the quality performance in landscape hydro-seeding construction by using a quantitative approach in which cost elements in the accounting system relating to costs of appraisal and costs of inspection were analysed. The investment in quality improvement initiatives in the past two years was examined. From the results obtained using prevention-appraisal-failure modelling method, the break-even point of the cost data from the company could not be identified, which makes it difficult to determine the balance between prevention, appraisal and failure costs. As a result, the company performance and efficiency could not be clearly identified. However, since the costs of prevention and appraisal are much higher than the costs of failure, this implicated that the company has already used several methods to improve the quality and to reduce failures.

The Vandermonde interpolation technique has been effectively used to show the break-even points in the total cost. The prevention and appraisal cost was shown to be periodic with small ripples, which means that the total cost is strongly dependent on the failure cost. From the results obtained 
in this paper, it is possible to control a random total cost by using simple periodic strategies as has been carried out by the company.

The main contributions of this paper are: i) To introduce a new Vandermonde interpolation technique to model prevention and appraisal cost, failure cost and total cost, ii) To compare the new method with the PAF modelling method; (iii) To clearly show break-even points in the total cost of a hydro-seeding company; (iv) To show that by applying periodic strategies for prevention and appraisal cost, it is possible to achieve desirable results; and (v) To show that techniques in the field of signal and image processing can be successfully applied to the field of quality management.

\section{Acknowledgement}

The authors would like to thank Toyo Greenland Company Limited for providing useful data for the research and for its support.

\section{References}

1. Abdul-Rahman, H; Some observations on the management of quality among construction professionals in the UK, Journal of Construction Management and Economics. 1996;14(6) 485-495.

2. Construction Industry Review Committee, Construct for excellence: report of the construction industry review committee: Hong Kong Government, 2001.

3. Love, EDP Li, H; Quantifying the causes and costs of rework in construction, Journal of Construction Management and Economics. 2000;18(4) 479-490.

4. Duncan, JM Thrope, B Sumner, P, Quality assurance in construction: Gower Publishing Company, 1990.

5. Hiyassat, MAS; Applying the ISO standards to a construction company: a case study, International Journal of Project Management. 2000;18(4) 275-280.

6. Campanella, J, Principles of quality costs: ASQC Quality Press, Milwaukee, 1990.

7. Carr, LP Ponemon, LA; The behaviour of quality costs: clarifying the confusion, Journal of Cost Management. 1994;8(2) 26-34. 
8. Deming, WE, Out of the crisis: MIT Center for Advanced Engineering Study, Cambridge, MA, 1986.

9. Greising, D; Quality: how to make it pay, Business Week. 1994;3384 54-59.

10. Hoover, HW; What went wrong in US. business's attempt to rescue its competitiveness? Quality Progress. 1995;28(7) 83-86.

11. Lackritz, JR; TQM within FORTUNE 500 corporations, Quality Progress. 1997;30(2) 69-72.

12. Metzger, LM; Measuring quality cost effects on productivity using data envelope analysis, Journal of Applied Business Research. 1993;9(3) 69-79.

13. Shank, JK Govindarajin, V; Measuring the 'cost of quality': a strategic cost management perspective, Journal of Cost Management. 1994;8(2) 5-17.

14. Tansey, R Carroll, FR Lin, ZJ; On measuring cost of quality dimensions: an exploratory study in the people's republic of china, International Business Review. 2001;10(2) 175-195.

15. Aoieong, RT Tang, SL Ahmed, SM; A process approach in measuring quality costs of construction projects: model development, Journal of Construction Management and Economics. 2002;20(2) 179-192.

16. Ho, DTP. 2001. The cost of quality for landscape hydroseeding industry in Hong Kong SAR, in Department of Engineering, University of Warwick.

17. Tang, SL Aoieong, RT Admed, SM; The use of process cost model for measuring quality costs of construction projects: model testing, Construction Management and Economics. 2004;22(3) 263275.

18. Arditi, D Murat Gunaydin, H; Total quality management in the construction process, International Journal of Project Management. 1997;15(4) 235-243.

19. Schwalbe, K, Information Technoloy Project Management, 4th ed. Boston: Thomson Course Technology, 2006.

20. Harris, F McCaffer, R, Modern construction management, 5th ed. Oxford: BlackWell Publishing, 2004.

21. Thomas, B, Total quality raining, the quality culture and quality trainer: The Mcgraw-hill Training Series, Series Editor: Roger Bennett, 1992.

22. Tam, CM Deng, ZM Zeng, SX; Evaluation of construction methods and performance for high rise public housing construction in Hong Kong, Building and Environment. 2002;37 983-991. 
23. Aoieong, RT Tang, SL Admed, SM; A process approach in measuring quality costs of construction projects: model development, Construction Management and Economics. 2002;20(2) 179-192.

24. Zhao, J; An optimal quality cost model, Applied Economics Letters. 2000;7(6) 185-188.

25. Hall, M Tomkins, C; A cost of quality analysis of a building project: towards a complete methodology for design and build, Journal of Construction Management and Economics. 2001;19(7) 727-740.

26. Toyo Greenland Company Limited, Hydro-seeding industry. http://www.toyogreen.com/ (2006).

27. Tam, WYV Le, KN; The six-sigma principle and prevention-appraisal-failure modeling for quality improvement in construction, Building and Environment. 2006; Article in press.

28. Press, WH Teukolsky, SA Vetterling, WT Flannery, BP, Numerical Recipes in C. New York: Cambridge University Press, 1994.

29. Foster, JST; An examination of the relationship between conformance and quality-related costs, International Journal of Quality and Reliability Management. 1996;13(4) 50-63. 
Table 1: Detailed Information Collected from the Survey

\begin{tabular}{|c|c|c|c|c|c|c|c|c|c|c|c|c|c|}
\hline & \multicolumn{10}{|c|}{ Prevention and Appraisal Cost (HK\$) } & \multicolumn{3}{|c|}{ Failure Cost (HK\$) } \\
\hline & Maintenance & Training & Consult & Books & $\begin{array}{c}\text { New } \\
\text { Machine }\end{array}$ & $\begin{array}{c}\text { New } \\
\text { Engineer }\end{array}$ & Inspect & Photo & Audit & Total & $\begin{array}{c}\text { Cost of } \\
\text { handling }\end{array}$ & $\begin{array}{l}\text { Cost of } \\
\text { rework }\end{array}$ & Total \\
\hline Apr-03 & $1,426.50$ & $1,400.00$ & $7,500.00$ & 699.95 & $4,687.5$ & $1,562.50$ & $2,950.00$ & 0.00 & $5,847.92$ & $26,074.37$ & $5,000.00$ & $2,800.00$ & $7,800.00$ \\
\hline May-03 & $3,515.00$ & $4,279.00$ & 0.00 & 79.00 & $4,687.5$ & $1,562.50$ & $6,450.00$ & 0.00 & $5,847.92$ & $26,420.92$ & $4,600.00$ & $4,335.00$ & $8,935.00$ \\
\hline Jun-03 & 664.00 & $2,139.00$ & $14,575.00$ & 0.00 & $4,687.5$ & $1,562.50$ & 450.00 & 0.00 & $5,847.92$ & $29,925.92$ & $2,200.00$ & 0.00 & $2,200.00$ \\
\hline Jul-03 & $8,787.50$ & $2,401.50$ & 0.00 & 275.50 & $4,687.5$ & $1,562.50$ & 0.00 & 0.00 & $5,847.92$ & $23,562.42$ & 0.00 & 0.00 & 0.00 \\
\hline Aug-03 & $1,310.00$ & $6,914.00$ & 0.00 & 223.50 & $4,687.5$ & $1,562.50$ & $3,750.00$ & 0.00 & $5,847.92$ & $24,295.42$ & $5,400.00$ & 0.00 & $5,400.00$ \\
\hline Sep-03 & $1,637.00$ & $4,814.30$ & $9,000.00$ & $1,067.25$ & $4,687.5$ & $1,562.50$ & 0.00 & 140.00 & $5,847.92$ & $28,756.47$ & $5,200.00$ & 0.00 & $5,200.00$ \\
\hline Oct-03 & $5,943.50$ & $9,795.00$ & 0.00 & 52.30 & $4,687.5$ & $1,562.50$ & $1,900.00$ & 0.00 & $5,847.92$ & $29,788.72$ & $3,200.00$ & $1,250.00$ & $4,450.00$ \\
\hline Nov-03 & $3,185.00$ & $6,045.00$ & $6,000.00$ & 20.00 & $4,687.5$ & $1,562.50$ & 0.00 & 0.00 & $5,847.92$ & $27,347.92$ & $7,000.00$ & $1,550.00$ & $8,550.00$ \\
\hline Dec-03 & $10,644.45$ & 525.00 & $3,875.00$ & $2,996.09$ & $4,687.5$ & $1,562.50$ & 0.00 & 91.40 & $5,847.92$ & $30,229.86$ & $5,000.00$ & $2,900.00$ & $7,900.00$ \\
\hline Jan-04 & $16,994.45$ & $5,770.00$ & 400.00 & 411.28 & $4,687.5$ & $1,562.50$ & 0.00 & 0.00 & $5,847.92$ & $35,673.65$ & $6,200.00$ & $1,850.00$ & $8,050.00$ \\
\hline Feb-04 & $7,823.25$ & $7,025.00$ & $6,000.00$ & 177.50 & $4,687.5$ & $1,562.50$ & 0.00 & 567.00 & $5,847.92$ & $33,690.67$ & $3,200.00$ & $3,350.00$ & $6,550.00$ \\
\hline Mar-04 & $6,048.50$ & 862.50 & 0.00 & 441.18 & $4,687.5$ & $1,562.50$ & 0.00 & $1,994.30$ & $5,847.92$ & $21,444.40$ & $3,000.00$ & 0.00 & $3,000.00$ \\
\hline Apr-04 & $1,511.75$ & 0.00 & $3,750.00$ & 0.00 & $4,687.5$ & $1,562.50$ & 0.00 & 117.50 & $5,847.92$ & $17,477.17$ & $1,000.00$ & 0.00 & $1,000.00$ \\
\hline May-04 & 102.00 & 225.00 & $5,000.00$ & 7.00 & $4,687.5$ & $1,562.50$ & 0.00 & 342.00 & $5,847.92$ & $17,773.92$ & $7,600.00$ & $19,475.00$ & $27,075.00$ \\
\hline Jun-04 & 62.50 & $3,057.50$ & 0.00 & 396.25 & $4,687.5$ & $1,562.50$ & 0.00 & 80.00 & $5,847.92$ & $15,694.17$ & $8,800.00$ & $56,133.50$ & $64,933.50$ \\
\hline Jul-04 & 37.50 & 0.00 & $3,000.00$ & 199.50 & $4,687.5$ & $1,562.50$ & 0.00 & 0.00 & $5,847.92$ & $15,334.92$ & $4,600.00$ & $9,050.00$ & $13,650.00$ \\
\hline Aug-04 & 105.75 & 125.00 & 0.00 & 242.20 & $4,687.5$ & $1,562.50$ & 3400 & 135.00 & $5,847.92$ & $16,105.87$ & $4,600.00$ & $9,050.00$ & $13,650.00$ \\
\hline Sep-04 & 877.75 & 0.00 & $5,250.00$ & 155.75 & $4,687.5$ & $1,562.50$ & 0 & $5,118.40$ & $5,847.92$ & $23,499.82$ & $9,900.00$ & $21,221.50$ & $31,121.50$ \\
\hline Oct-04 & 50.00 & $2,150.00$ & $18,500.00$ & $1,303.00$ & $4,687.5$ & $1,562.50$ & 0.00 & 86.40 & $5,847.92$ & $34,187.32$ & $5,600.00$ & $10,100.00$ & $15,700.00$ \\
\hline Nov-04 & 248.00 & 485.00 & $4,000.00$ & 485.50 & $4,687.5$ & $1,562.50$ & 3700 & 0.00 & $5,847.92$ & $21,016.42$ & $5,400.00$ & $4,900.00$ & $10,300.00$ \\
\hline Dec-04 & 55.00 & 900.00 & $7,087.50$ & 69.00 & $4,687.5$ & $1,562.50$ & 700 & 0.00 & $5,847.92$ & $20,909.42$ & $5,400.00$ & $7,320.00$ & $12,720.00$ \\
\hline Jan-05 & $2,578.25$ & $1,874.90$ & $4,200.00$ & 432.50 & $4,687.5$ & $1,562.50$ & 3400 & 0.00 & $5,847.92$ & $24,583.57$ & $9,800.00$ & $24,600.50$ & $34,400.50$ \\
\hline Feb-05 & 475.00 & 682.68 & $4,000.00$ & 300.00 & $4,687.5$ & $1,562.50$ & 350 & 10.00 & $5,847.92$ & $17,915.60$ & $3,100.00$ & $6,388.50$ & $9,488.50$ \\
\hline Mar-05 & $5,623.65$ & 25.00 & $4,000.00$ & 443.97 & $4,687.5$ & $1,562.50$ & 0 & $3,754.00$ & $5,847.92$ & $25,944.54$ & $2,200.00$ & $6,609.50$ & $8,809.50$ \\
\hline
\end{tabular}




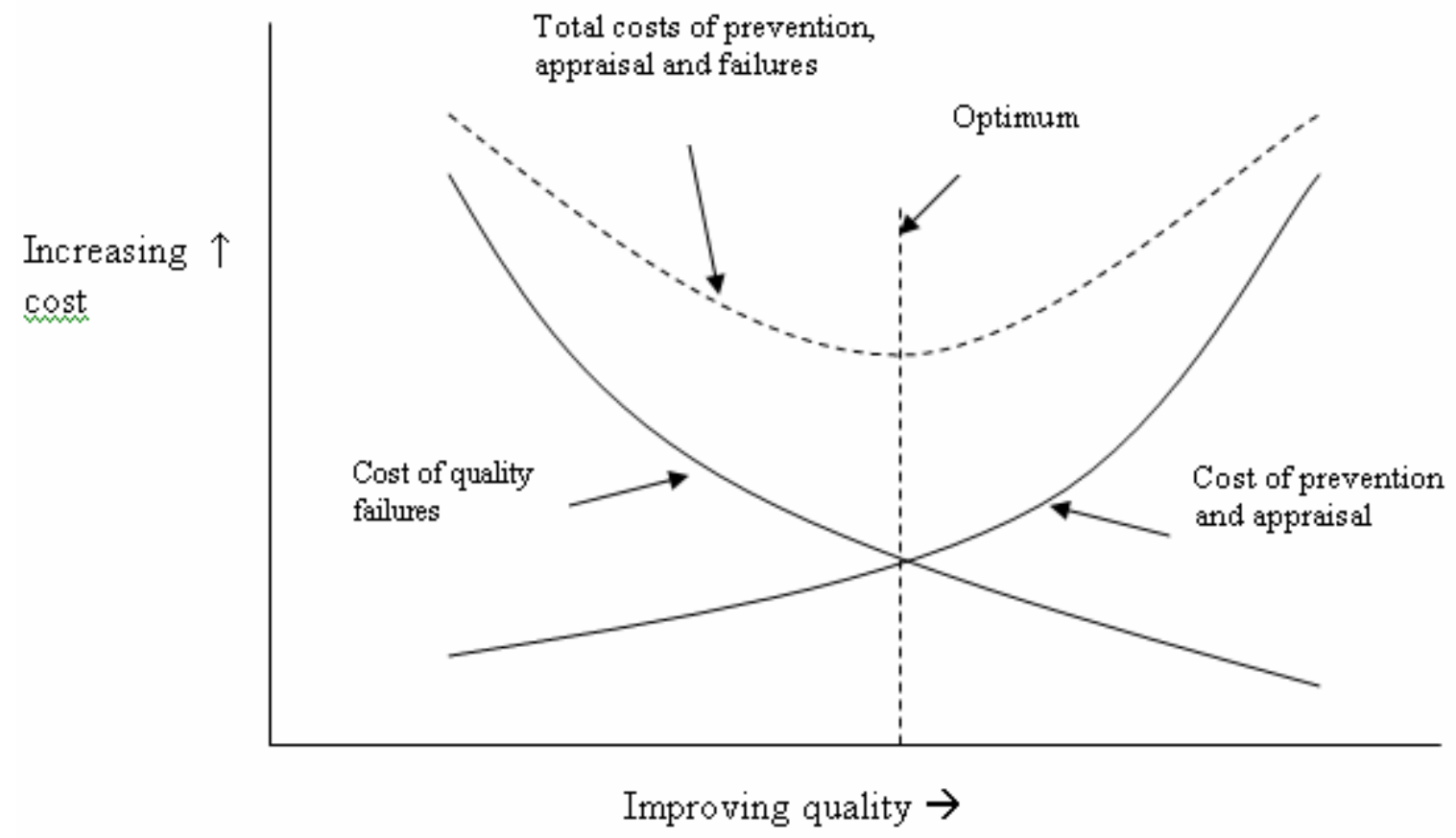

Figure 1: Optimization of Quality and Cost [29] 


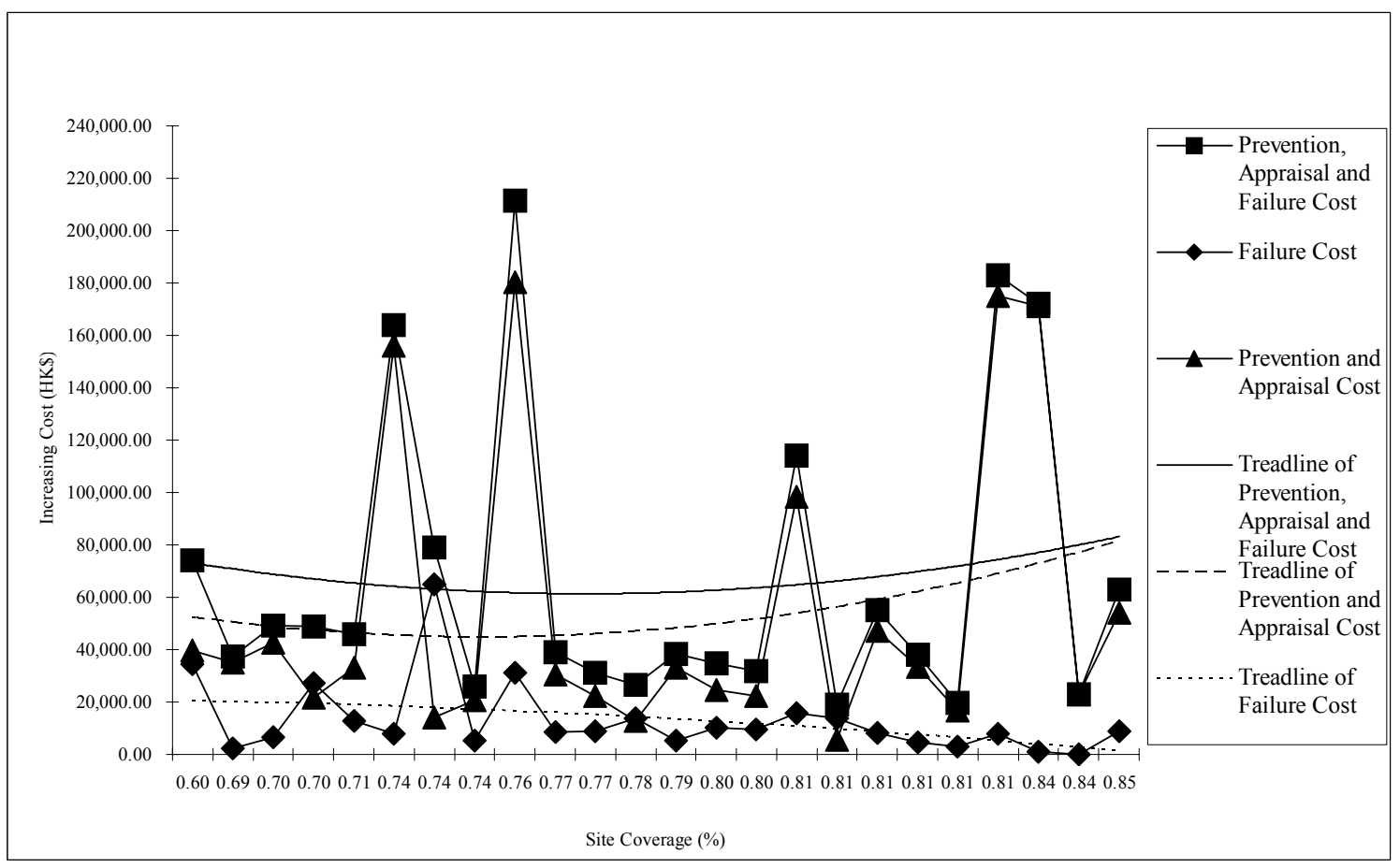

Figure 2: PAF Model of Hydro-seeding Projects During April 2003 to March 2005

(Cost Against Quality: Site Coverage Basis) 


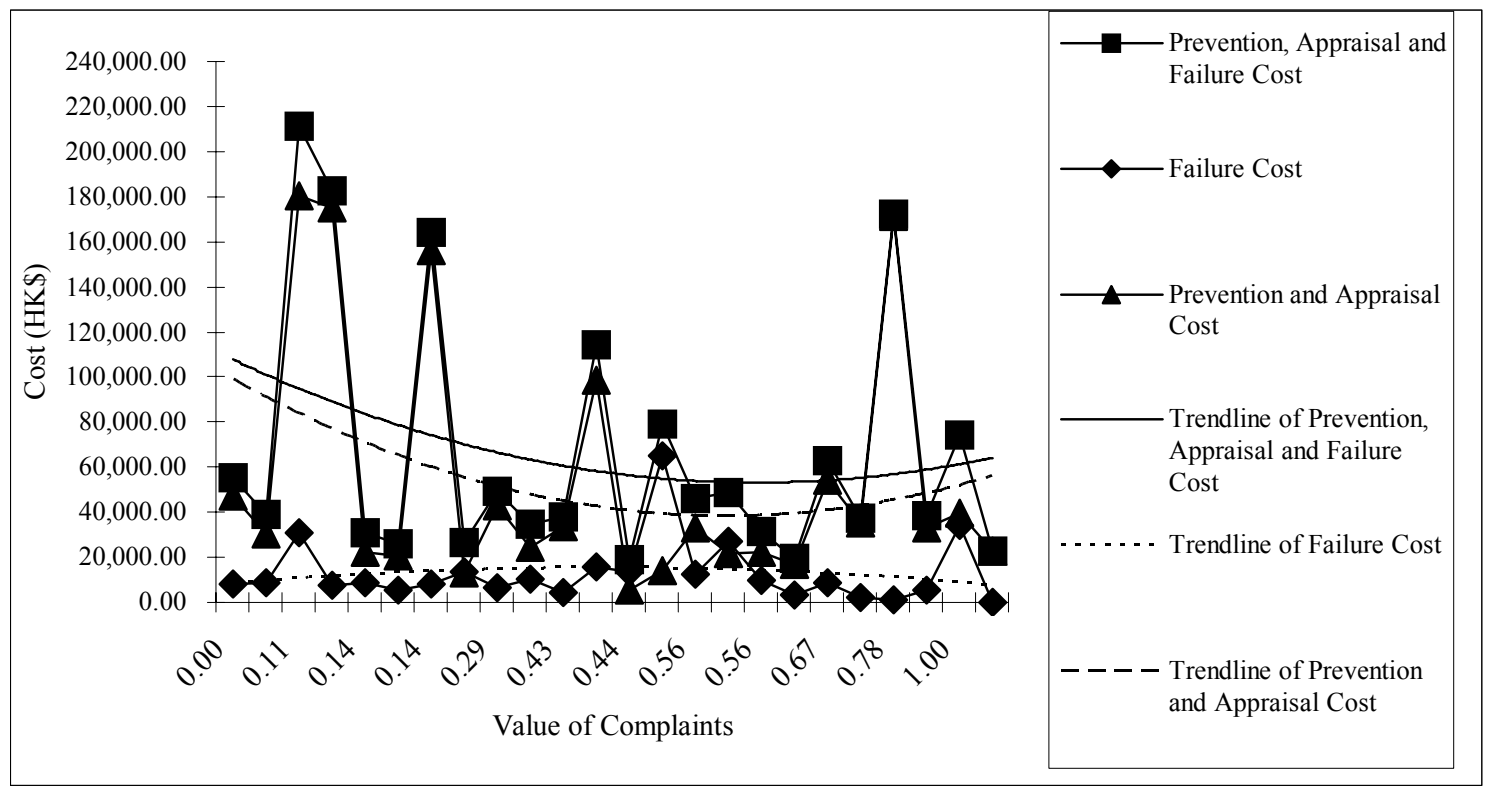

Figure 3: PAF Model of Hydro-seeding Projects During April 2003 to March 2005 (Cost Against Quality: Complaints) 


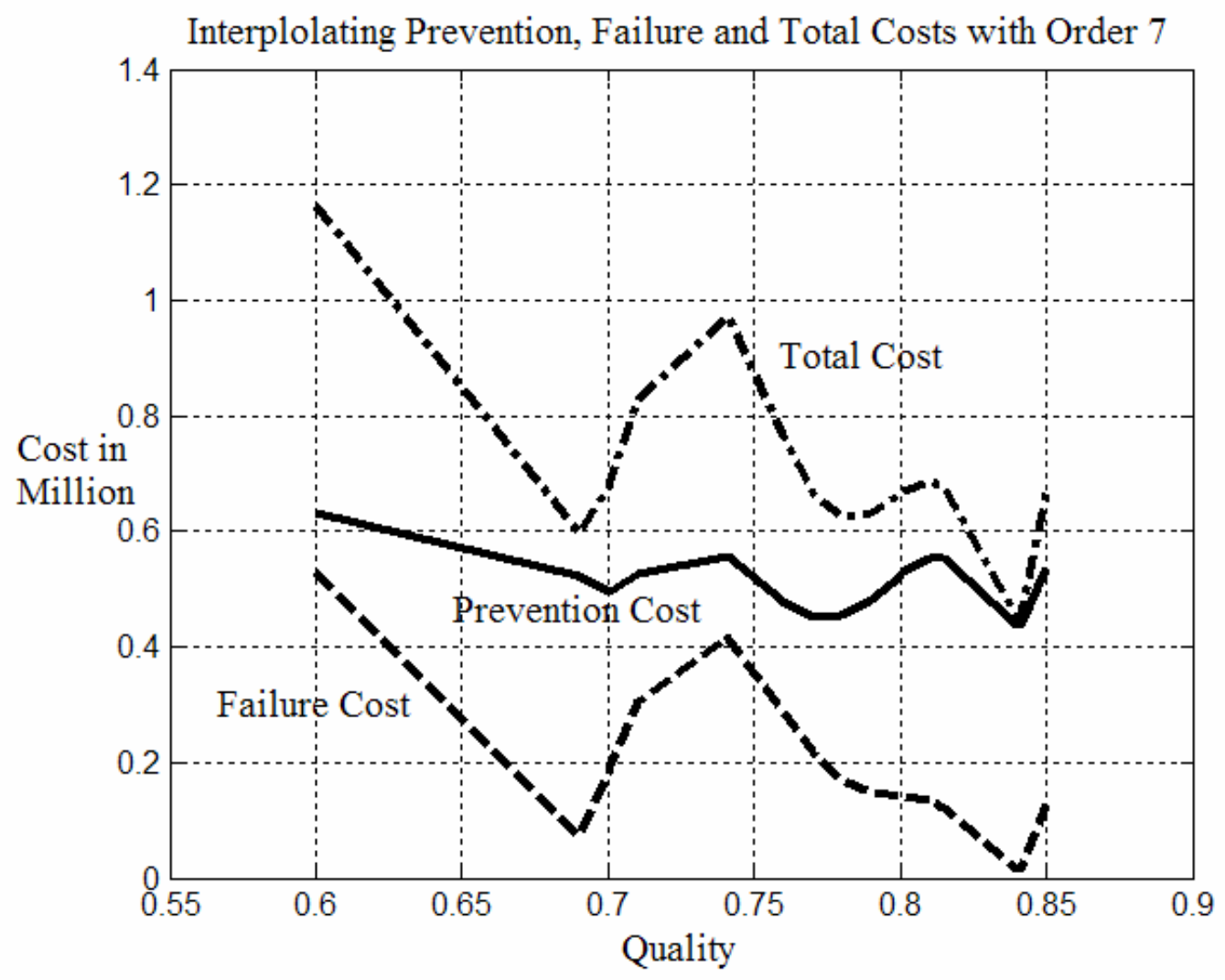

Figure 4: Interpolation of Prevention and Appraisal, Failure and Total Costs using a $7^{\text {th }}$ order polynomial 